\title{
Preferential Localization of Iron in The Chromatin of Fe-Enriched Cells Is Linked to DNA Cleavage Sites and Control of Carcinogenesis
}

Clelia Rejane Antonio Bertoncini ${ }^{1 *}$, Rogerio Meneghini², Fernando Galembeck ${ }^{3}$, Michele Longoni Calió ${ }^{4}$, Adriana Ferraz Carbonel $^{5}$ and Rodrigo Aquino de Castro ${ }^{6}$

${ }^{1}$ CEDEME, Universidade Federal de São Paulo, São Paulo, SP, Brasil

${ }^{2}$ SciELO, Scientific Electronic Library Online, Brasil

Instituto de Química, Universidade Estadual de Campinas, Brasil

${ }^{4}$ Departamento de Bioquímica, Universidade Federal de São Paulo, Brasil

${ }^{5}$ Departamento de Morfologia, Universidade Federal de São Paulo, Brasil

${ }^{6}$ Departamento de Ginecologia, Universidade Federal de São Paulo, São Paulo, Brasil

\begin{abstract}
DNA oxidation by oxygen-radicals generated via an iron catalyzed Fenton reaction has been extensively investigated, but little is known about iron localization in the nuclei of mammalian cells. In vitro studies showed the presence of five oxygen and one nitrogen atoms in the inner coordination sphere of the Fe(II)-DNA complex using X-ray absorption spectroscopy (XANES and EXAFS). The identification of ferritin in the nucleus of cultured cells, as well as iron-protein receptors in the nuclear membrane suggests that iron is actively transported into the nucleus. Therefore, pictures from energy-loss spectroscopic imaging (ESI) are included in this mini-review to illustrate the distribution of iron in a fibroblast cell line. These fibroblasts were iron-overloaded by being cultured in a medium containing $\mathrm{Fe}(\mathrm{III})$-nitrilotriacetate (FeNTA). The elemental mapping of iron and phosphorus was coincident in ultrastructures and revealed a significant concentration of both in condensed chromatin; by contrast, the elemental mapping of nitrogen, used as a control, revealed a homogenous distribution across the entire cell. This observed preferential localization was surprising, considering the pro-oxidant status of iron and the importance of maintaining genome integrity. Interestingly, recent published works demonstrates that iron chelators such as genistein and daidzein, derived from soy isoflavones, can attenuate the expression of genes related to increased cancer risk and oxidative damage in the reproductive tract of female mice. In this same sense, mesenchymal stem cells also exhibit antioxidant properties by reducing superoxide, lipid peroxidation, and DNA breaks to healthful levels after transplantation into the brains of stroke prone spontaneously hypertensive rats. Therefore, we bring attention to the use of all potential antioxidants, particularly those with affinity for both iron and DNA, in therapies for several diseases.
\end{abstract}

Keywords: Antioxidants; DNA; Elemental mapping; Iron; Nucleus; Cancer risk

\section{Introduction}

\section{The interaction between iron and DNA into the nucleus}

Iron uptake in mammalian cells has been extensively investigated and has revealed a post-transcriptional control mechanism regulating the transferrin receptor and ferritin synthesis [1-4]. Cytosolic iron is strictly controlled, with most of the spare iron being stored as ferritin in a non-reactive form. However, the distribution of cellular iron is still unresolved. In particular, little is known about iron localization in the nucleus. This is an important question, given the fact that the process of DNA oxidation by oxy-radicals is catalyzed by nuclear iron [5], which can produces DNA strand breaks even in the presence of physiological concentrations of hydrogen peroxide (Supplementary Figure 1).

Nuclear iron has been found in several forms, either associated with ferritin as a heme complex that regulates gene expression, or in the nucleus in the form of iron-sulfur clusters associated with DNA repair enzymes and transcription factors [1-4]. Furthermore, mimetic nucleases, such as FeIII ZnII (-Purple acid phosphatase models) are relevant to DNA cleavage and cytotoxic activity [6], which could be interesting for cancer chemotherapy.

In our previous in vitro studies, $\mathrm{X}$-ray absorption spectroscopy was used to provide evidence of five oxygen and one nitrogen atoms in the inner coordination sphere of Fe(II)-DNA, while Fe III preferentially binds only to oxygen atoms $[7,8]$.

Herein, we emphasize the use of elemental mapping analysis to illustrate the distribution of iron in the nucleus with electron energyloss spectroscopic imaging (ESI). This technique allows specific localization of atoms at the ultra-structural level $[9,10]$. Herein, we emphasize the elemental mapping analysis to illustrate the distribution of iron in the nucleus by using electron energy-loss spectroscopic imaging (ESI). This technique allows specific localization of atoms at the ultra-structural level $[9,10]$. For this purpose, V79 Chinese hamster fibroblasts were grown in culture. In order to augment cellular iron uptake, $1 \mathrm{mM} \mathrm{Fe}$ (III)-nitrilotriacetate (FeNTA) was added to the medium for $2 \mathrm{~h}$, as previously described [5]. The cell layers were washed three times with $100 \mu \mathrm{M} \mathrm{K}$-phosphate buffer, $\mathrm{pH}$ 7.4, containing 140 $\mathrm{mM} \mathrm{NaCl}$ and the cells were fixed for $1 \mathrm{~h}$ at room temperature with $2.5(\mathrm{v} / \mathrm{v})$ glutaraldehyde plus $1 \%$ paraformaldehyde in $0.1 \mathrm{M}$ cacodylate buffer, $\mathrm{pH}$ 7.3. After rinsing with the same buffer, cells were post-fixed

*Corresponding author: Antonio Bertoncic CR, CEDEME, Centro de Desenvolvimento de Modelos Experimentais para Medicina e Biologia, Universidade Federal de São Paulo (UNIFESP), Escola Paulista de Medicina Rua Botucatu, 862, São Paulo, SP, 04023-900, Brasil, Tel/Fax: +55 11 55764558; E-mail: clelia.rejane@unifesp.br, cleliabertoncini@hotmail.com

Received December 21, 2015; Accepted August 29, 2016; Published August 31, 2016

Citation: Bertoncini CRA, Meneghini R, Galembeck F, Calió ML, Carbonel AF, et al. (2016) Preferential Localization of Iron in The Chromatin of Fe-Enriched Cells Is Linked to DNA Cleavage Sites and Control of Carcinogenesis. J Cancer Sci Ther 8: 213-215. doi:10.4172/1948-5956.1000415

Copyright: $\odot 2016$ Bertoncini CRA, et al. This is an open-access article distributed under the terms of the Creative Commons Attribution License, which permits unrestricted use, distribution, and reproduction in any medium, provided the original author and source are credited. 
Citation: Bertoncini CRA, Meneghini R, Galembeck F, Calió ML, Carbonel AF, et al. (2016) Preferential Localization of Iron in The Chromatin of Fe-Enriched Cells Is Linked to DNA Cleavage Sites and Control of Carcinogenesis. J Cancer Sci Ther 8: 213-215. doi:10.4172/19485956.1000415

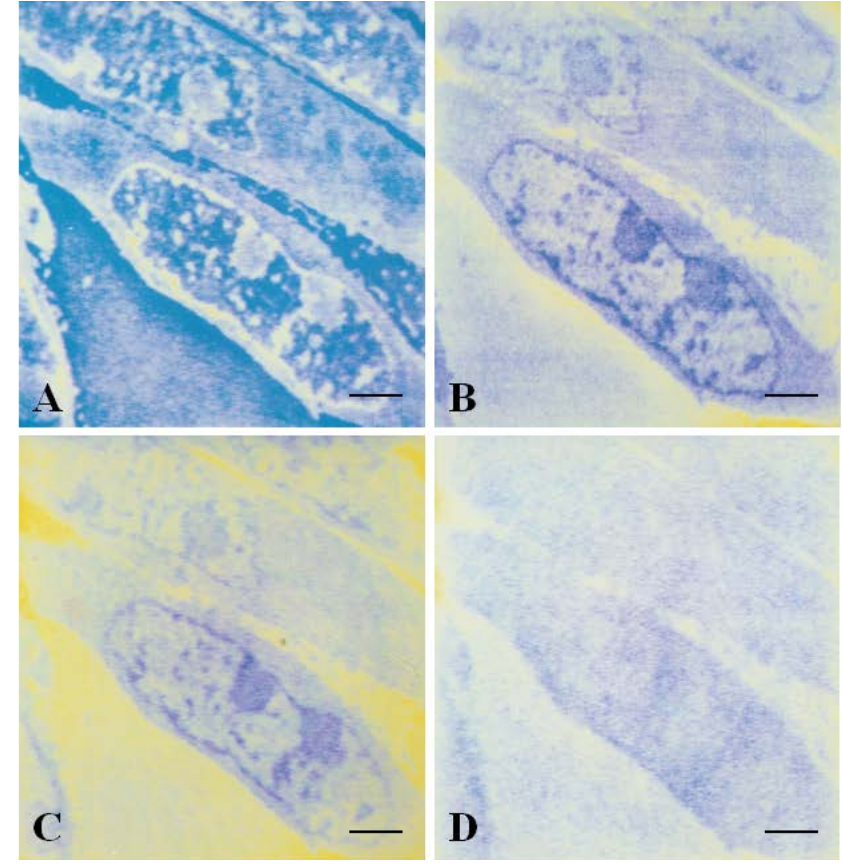

Figure 1: Elemental mapping by electron energy-loss spectroscopic imaging (ESI) in fibroblasts; $1 \mathrm{mM}$ FeNTA was added to the medium and the cells were incubated for $2 \mathrm{~h}$. A: bright field (zero-loss filtered); B: iron; C: phosphorus; D: nitrogen. Bar=1.2 $\mu \mathrm{m}$.

in $1 \%$ osmium tetraoxide in cacodylate buffer for $1 \mathrm{~h}$, and stained overnight in $0.5 \%(\mathrm{w} / \mathrm{v})$ aqueous uranyl acetate, at $4^{\circ} \mathrm{C}$. Samples were then washed, dehydrated in ethanol, and embedded in Spurrs resin. Sections approximately $100 \mathrm{~nm}$ thick were stained with uranyl acetate and lead citrate and examined in a Zeiss CEM902 transmission electron microscope integrated with a Castaing-Henry electron spectrometer. The images were collected on a silicon intensifier target that interfaced with a digital image analysis system. The microscope was operated at 80 $\mathrm{kV}$ and the objective aperture was set to $30 \mu \mathrm{m}$ for the bright field and to $90 \mu \mathrm{m}$ for the ESI. Both the bright field (zero-loss filtered) and the ESI were obtained with $\mathrm{E}=20 \mathrm{eV}$ width at the spectrometer slit.

Elemental mapping was done with computer-assisted image processing (CEM20 program using the ELEMECZ routine). Image subtraction, background correction and contrast inversion were performed with the software IBAS rel-2.0 (Kontron). The elements mapped were Iron (energy loss threshold at $708 \mathrm{eV}$ ), Phosphorus (132 $\mathrm{eV})$ and Nitrogen $(401 \mathrm{eV})$. Dark areas in the elemental maps are richer in the mapped element. The images were recorded in $35 \mathrm{~mm}$ slides within a Montage film recorder.

\section{Elemental mapping analysis}

Figure 1 shows the distribution of iron in the nucleus using electron energy-loss spectroscopic imaging (ESI). A typical set of elemental mapping images of $100 \mathrm{~nm}$ thick sections of fibroblasts. Figure $1 \mathrm{~A}$ is the digital bright field image (zero loss-filtered) of a section in which the characteristic spindle shape of the fibroblasts is shown and the elliptical nucleus is clearly defined. Figure 1B-1D corresponds to elemental mapping of iron, phosphorus and nitrogen. In these elemental maps, element-rich areas are dark, while element-poor regions are clear. In Figure 1B, at this magnification the iron mapping reveals a homogenous distribution of this element in the cytosol. In contrast, iron is discretely distributed in the nucleus, being clearly concentrated in chromatin grains, in the nucleic acid-enriched nucleoli and in the nuclear membrane region. Interestingly, the phosphorus mapping in Figure $1 \mathrm{C}$ depicts a distribution that is essentially coincident with that of iron. Indeed, this is the image that one would expect for cellular phosphorus, given its abundant presence in nucleic acids. The intensely labeled region in the nuclear periphery is due to condensed chromatin, known to be preferentially associated with the nuclear membrane, and has little or no contribution from membrane phospholipids. In fact, at this magnification the plasma membrane cannot be identified. In Figure 1D the nitrogen image is shown as a control, representing an atom that is not preferentially distributed in any sub-cellular structure, as mapped by ESI.

\section{Possible functions of the iron-chromatin DNA interaction}

Iron-containing repair enzymes [4,11] and iron-containing transcription factors [12] have been identified in bacteria and heme is involved in transcriptional activation in yeast [13]. However these elements are unlikely to account for the iron-enriched mammalian chromatin.

Indeed, the function of iron bound to chromatin is a matter of controversy. For instance, one possibility is that iron, like copper, is an important element in the maintenance of chromosome structure [14]. As expected, preferential sites of iron-DNA interaction were localized in upstream regulatory regions of many genes involved in oxidative stress [15]. In another in vitro study concerned with $\mathrm{Fe}^{2+}$ mediated Fenton reactions at human telomere inserts, 7 fold more strand breakage occurred in the telomeres than in a similar-sized coding control fragment [16]. These results were interpreted to mean that telomeric DNA may protect coding DNA from oxidative damage and might also link oxidative damage and iron load to telomere shortening and aging.

Thus, the observed preferential localization revealed by the ISI technique in fixed cultured cells is somewhat surprising, considering the pro-oxidant status of iron and the importance of maintaining genome integrity. Interestingly, we recently demonstrated that bone marrow mesenchymal stem cells exhibit antioxidant properties by reducing superoxide, lipid peroxidation and DNA breaks to healthful levels after transplantation to the brains of stroke prone hypertensive rats [17]. In the same sense, iron chelators, such as soy isoflavones extracts or their purified derivatives genistein and daidzein $[18,19]$, counteract oxidative damages [20] and attenuate the expression of genes related to cancer risk [21] in the reproductive tract of female mice. We do not know if iron-chromatin or iron-isoflavone complexes are implied in the case of menopausal cancer preventive therapies. However, the previously observed localization of iron and DNA in the nucleus of neuronal cells by confocal microscopy [22] suggests the possible involvement of neural iron-chromatin in the case of stroke associated with oxidative stress [17]. An interesting and current state of the art study also demonstrates that low doses of added extracellular iron stimulates cellular responses, which are significant enough to modify the vascular endothelium, and induces gene expression of DNA damage repair enzymes and p53 stabilization [23]. Given that the required amounts of iron decrease during ageing, the fine control of body iron stores would be a wise strategy for control of carcinogenesis [24,25].

Therefore, we direct attention to all potential antioxidants, particularly those with affinity both to iron and DNA, in therapies for several diseases.

\section{Acknowledgments}

This work was supported by grants from FAPESP (Fundação de Amparo 
Citation: Bertoncini CRA, Meneghini R, Galembeck F, Calió ML, Carbonel AF, et al. (2016) Preferential Localization of Iron in The Chromatin of Fe-Enriched Cells Is Linked to DNA Cleavage Sites and Control of Carcinogenesis. J Cancer Sci Ther 8: 213-215. doi:10.4172/19485956.1000415

a Pesquisa do Estado de São Paulo) and CNPq (Conselho Nacional de Desenvolvimento Científico e Tecnológico). We are grateful to Dr. Carlos A. Leite for his help in image acquisition.

\section{References}

1. De Freitas JM, Meneghini R (2001) Iron and its sensitive balance in the cell. Mutat Res 475: 153-159.

2. Clothier B, Robinson S, Akhtar RA, Francis JE, Peters TJ, et al. (2000) Genetic variation of basal iron status, ferritin and iron regulatory protein in mice: potential for modulation of oxidative stress. Biochem Pharmacol 59: 115-122.

3. Kobayashi K, Fujikawa M, Kozawa T (2015) Binding of promoter DNA to SoxR protein decreases the reduction potential of the [2Fe-2S] cluster. Biochemistry 54: $334-339$

4. Kuo CF, McRee DE, Fisher CL, O'Handley SF, Cunningham RP, et al. (1992) Atomic structure of the DNA repair [4Fe-4S] enzyme endonuclease III. Science 258: 434-440.

5. Bertoncini CR, Meneghini R (1995) DNA strand breaks produced by oxidative stress in mammalian cells exhibit 3'-phosphoglycolate termini. Nucleic Acids Res 23: 2995-3002.

6. Peralta RA, Bortoluzzi AJ, de Souza B, Jovito R, Xavier FR, et al. (2010) Electronic structure and spectro-structural correlations of $\mathrm{Fe}(\mathrm{III}) \mathrm{Zn}(\mathrm{II})$ biomimetics for purple acid phosphatases: relevance to DNA cleavage and cytotoxic activity. Inorg Chem 49: 11421-11438.

7. Bertoncini C, Meneghini R, Cruz DZ, Martins Alves MC, Tolentino H (1999) Studies of $\mathrm{Fe}$ (II) and Fe(III)-DNA complexes by XANES spectroscopy. J Synchrotron Radiat 6: 417-418.

8. Bertoncini CRA, Meneghini R, Tolentino H (2010) Nearest-neighbor nitrogen and oxygen distances in the iron(II)-DNA complex studied by extended X-ray absorption fine structure. Spectrochimica Acta A 77: 908-910

9. Bazett-Jones DP, Hendzel MJ (1999) Electron spectroscopic imaging of chromatin. Methods 17: 188-200.

10. Liu D, Kottke I (2003) Subcellular localization of chromium and nickel in root cells of Allium cepa by EELS and ESI. Cell Biol Toxicol 19: 299-311.

11. Boal AK, Yavin E, Lukianova AO, O'Shea VL, David SS, et al. (2005) DNAbound redox activity of DNA repair glycosylases containing [4Fe-4S] clusters. Biochemistry 44: 8397-407.

12. Watanabe S, Kita A, Kobayashi K, Miki K (2008) Crystal structure of the [2Fe2S] oxidative-stress sensor SoxR bound to DNA. Proc Natl Acad Sci U S A 105: $4121-4126$
13. Hickman MJ, Winston F (2007) Heme levels switch the function of Hap1 of Saccharomyces cerevisiae between transcriptional activator and transcriptional repressor. Mol Cell Biol 27: 7414-24.

14. Marsden MP, Laemmli UK (1979) Metaphase chromosome structure: evidence for a radial loop model. Cell 17: 849-858.

15. Rai P, Cole TD, Wemmer DE, Linn S (2001) Localization of Fe(2+) at an RTGR sequence within a DNA duplex explains preferential cleavage by $\mathrm{Fe}(2+)$ and H2O2. J Mol Biol 312: 1089-1101.

16. Henle ES, Han Z, Tang N, Rai P, Luo Y, et al. (1999) Sequence-specific DNA cleavage by $\mathrm{Fe} 2+-$ mediated fenton reactions has possible biological implications. J Biol Chem 274: 962-71.

17. Calió ML, Marinho DS, Ko GM, Rodrigues R, Carbonel AF, et al. (2014) Transplantation of bone marrow mesenchymal stem cells decreases oxidative stress, apoptosis, and hippocampal damage in brain of a spontaneous stroke model. Free Radic Biol Med 70: 141-54

18. Dowling S, Regan F, Hughes $H(2010)$ The characterization of structural and antioxidant properties of isoflavone metal chelates. J Inorg Biochem 104: 1091 1098.

19. Mira L, Fernandez MT, Santos M, Rocha R, Florêncio MH, et al. (2002) Interactions of flavonoids with iron and copper ions: a mechanism for their antioxidant activity. Free Radic Res 36: 1199-1208.

20. Teixeira CP, Simões RS, Santos MA, Calió ML, Soares JM Jr, et al. (2014) Soybean concentrated extract counteracts oxidative stress in the uterus of rats. Climacteric 17: 402-409.

21. Carbonel AA, Calió ML, Santos MA, Bertoncini CR, Sasso Gda S, et al. (2015) Soybean isoflavones attenuate the expression of genes related to endometrial cancer risk. Climacteric 18: 389-398.

22. Quintana C, Bellefqih S, Laval JY, Gerquin-Kern JL, Wu TD, et al. (2006) Study of the localization of iron, ferritin, and hemosiderin in Alzheimer's disease hippocampus by analytical microscopy at the subcellular level. J Struct Bio 153: 42-54.

23. Mollet IG, Patel D, Govani FS, Gless A, Paschalaki K, et al. (2016) Low dose iron treatments induce a DNA damage response in human endothelial cells within minutes. PloS One 11: e0147990.

24. Kabat GC, Rohan TE (2007) Does excess iron play a role in breast carcinogenesis? An unresolved hypothesis. Cancer Causes Control 18 1047-1053.

25. Toyokuni S (2011) Iron as a target of chemoprevention for longevity in humans Free Radic Res 45: 906-917. 